\title{
Piston Wetting in an Optical DISI Engine: Fuel Films, Pool Fires, and Soot Generation
}

\author{
The submitted manusoript has bees \\ authored by a contractor of the UnitedEric Stevens ${ }^{*}$ and Richard Steeper \\ States Government undex contrack. \\ Accordingly the United States Gov- \\ ernment retains a non-exclusive. \\ Copyright $(92001$ Society of Automotive Engineers, Inc. royalty-free license to publish or re- \\ produce the published form of this \\ contribution, or allow others to do so \\ for United States Government pare
} pases.

\section{ABSTRACT}

Piston-wetting effects are investigated in an optical direct-injection spark-ignition (DISI) engine. Fuel spray impingement on the piston leads to the formation of fuel films, which are visualized with a laser-induced fluorescence (LIF) imaging technique. Oxygen quenching is found to reduce the fluorescence yield from liquid gasoline. Fuel films that exist during combustion of the premixed charge ignite to create piston-top pool fires. These fires are characterized using direct flame imaging. Soot produced by the pool fires is imaged using laser elastic scattering and is found to persist throughout the exhaust stroke, implying that piston-top pool fires are a likely source of engine-out particulate emissions for DISI engines.

\section{INTRODUCTION}

In direct-injection spark-ignition (DISI) engines, fuel is injected directly into the cylinder, increasing the likelihood of spray impingement on piston and cylinder surfaces. In fact, many stratified-charge strategies rely on shaped pistons to direct the fuel spray to the vicinity of the spark plugs [1]. Under these conditions, as well as in the case of unintentional fuel impingement during homogeneous charge operation, fuel films can form on the piston, with significant implications for combustion performance.

If such films persist until combustion of the premixed charge in the cylinder, they may ignite and burn as diffusion flames. In an optical engine, they are prominently visible as bright yellow flames often persisting through the expansion stroke. Evidence of burning fuel films has previously been presented for port-fuel-injected (PFI) engines [2-5]. Using an optical piston, Witze, et al. [6] presented visible-light images of burning films in a PFI engine that were assigned the label pool fires. The occurrence of pool fires in DISI engines has not been discussed widely in the literature $[1,7]$.
This work examines fuel films that are formed on a DISI piston by spray impingement, pool fires that result when these films ignite, and particulate matter generated during burning of the pool fires. These phenomena are of general interest since they are likely to occur in a variety of DISI engine configurations.

The paper begins with a brief description of the research engine and optical diagnostics used for the experiments. Data presented include laser-induced fluorescence (LIF) images of fuel spray impingement and piston-top fuel films. Images of visible flame luminosity are presented to characterize the development of pool fires and illustrate conditions under which they are likely to occur. Finally, laser elastic scattering from soot is used to demonstrate the implications of these pool fires on particulate emissions from a DISI engine.

\section{OPTICAL ENGINE}

The single-cylinder, optical DISI engine used for these experiments is shown in Figure 1 and was described in a previous paper [8]. It consists of a Labeco CLR singlecylinder base engine with an extended Bowditch piston and a four-cylinder, General Motors prototype DISI head. The design incorporates a rapid-acting drop-down cylinder to facilitate cleaning of optical surfaces.

The research engine accommodates two different cylinders. The first is fabricated completely of UV-grade fused silica, permitting optical access to the full swept volume. The second is a two-part cylinder comprising a one-inch-high fused silica ring atop a water-cooled steel cylinder. The all-quartz cylinder does not permit effective control of cylinder temperature, limiting experiments to 3 4 minutes of fired operation. The two-part cylinder allows temperatures to be controlled more tightly, while providing optical access to the top portion of the cylinder. Using the two-part cylinder, extended fired operation is possible. Both cylinders accommodate a Bowditch piston with a 65-mm-diameter quartz window. The piston top is flat to maximize optical access and enable studies of phenomena common to a range of DISI engine designs.

\footnotetext{
${ }^{*}$ Currently at GE Aircraft Engines, Cincinnati, $\mathrm{OH}$.
} 


\section{DISCLAIMER}

This report was prepared as an account of work sponsored by an agency of the United States Government. Neither the United States Government nor any agency thereof, nor any of their employees, make any warranty, express or implied, or assumes any legal liability or responsibility for the accuracy, completeness, or usefulness of any information, apparatus, product, or process disclosed, or represents that its use would not infringe privately owned rights. Reference herein to any specific commercial product, process, or service by trade name, trademark, manufacturer, or otherwise does not necessarily constitute or imply its endorsement, recommendation, or favoring by the United States Government or any agency thereof. The views and opinions of authors expressed herein do not necessarily state or reflect those of the United States Government or any agency thereof. 


\section{DISCLAIMER}

Portions of this document may be illegible in electronic image products. Images are produced from the best available original document. 


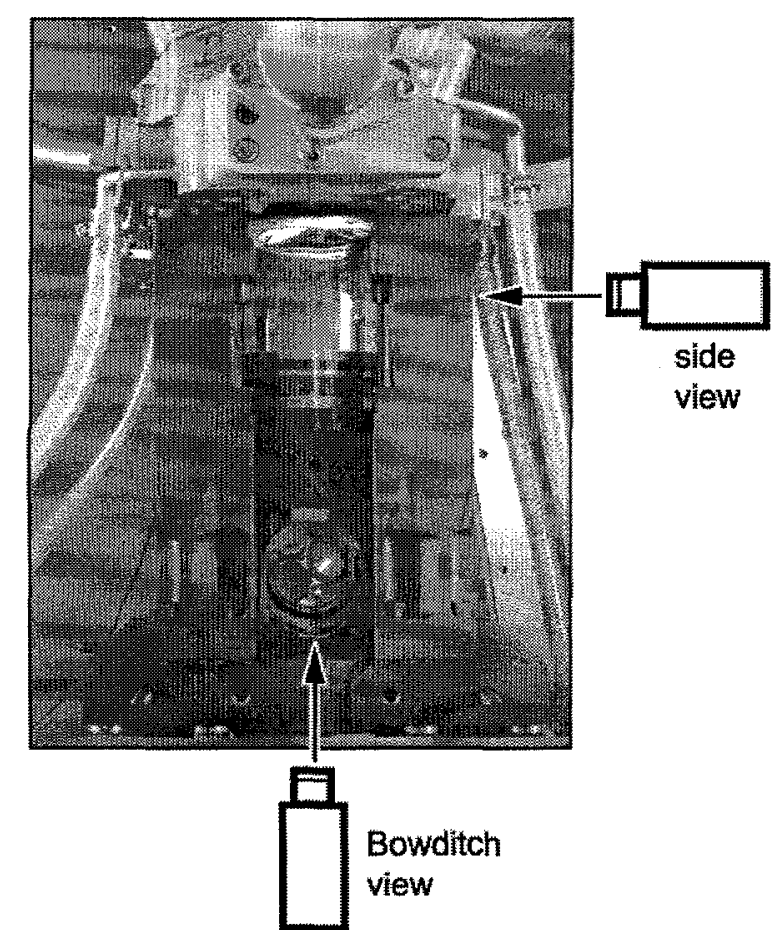

Figure 1: Optical DISI engine with full quartz cylinder. Typical camera positions for imaging in-cylinder processes are also shown.

A bottom view of the DISI head is shown in Figure 2. It contains four combustion chambers, although only one is used. The chamber has a pent roof with two intake valves, one exhaust valve, and two spark plugs. The fuel injector, a Zexel $30^{\circ}$ pressure-swirl injector, is mounted near the center of the bore, and the spray is directed vertically downward. A throttle valve in the secondary intake port can be used to alter the intake flow, but it has been left open for these experiments.

The engine specifications and operating conditions are summarized in Table 1. Unless otherwise noted, the head temperature for all experiments is maintained at 90 ${ }^{\circ} \mathrm{C}$. A skip-firing procedure, described previously [8], controls piston temperatures to match those measured for a comparable multi-cylinder production engine at similar speed and load [9]. In this procedure, the engine is motored for 90 cycles and then fired for 10 cycles using the 96-octane, unleaded test gasoline (UTG-96) listed in Table 1. This sequence is repeated and data are recorded on the last fired cycle of each sequence. At the

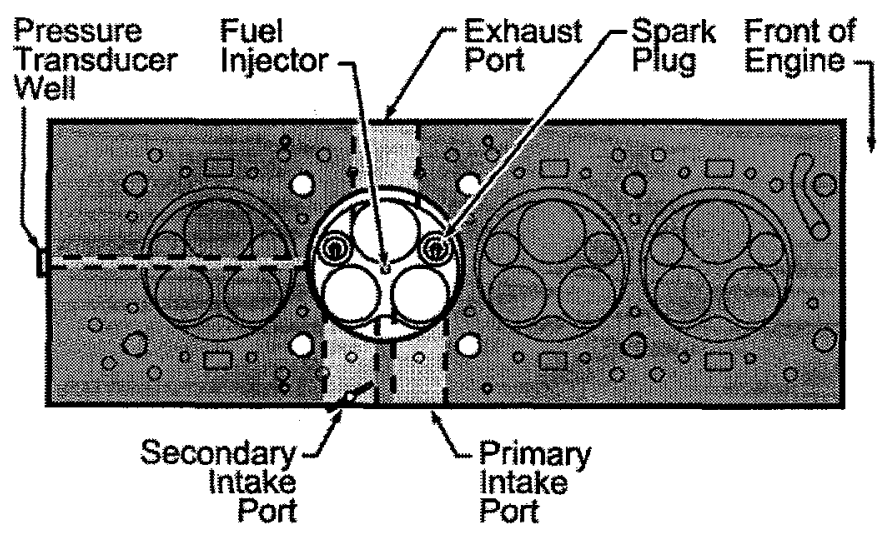

Figure 2: Bottom view of the 4-cylinder DISI head.
Table 1: Engine specifications and typical operating conditions.

\begin{tabular}{|ll|}
\hline bore & $92 \mathrm{~mm}$ \\
stroke & $85 \mathrm{~mm}$ \\
compression ratio & 9.32 \\
fuel & Phillips UTG-96 \\
fuel injector & Zexel $30^{\circ}$ swirl \\
fuel pressure & $5 \mathrm{MPa}$ \\
injection duration & $1.57 \mathrm{~ms}$ \\
engine speed & $1300 \mathrm{rpm}$ \\
fuel equivalence ratio & 0.77 \\
manifold absolute pressure & $54 \mathrm{kPa}$ \\
head temperature & $90^{\circ} \mathrm{C}$ \\
piston temperature & $\sim 150^{\circ} \mathrm{C}$ \\
\hline
\end{tabular}

start of each experiment, the engine is skip-fired with propane for one minute to warm up the engine without soiling optical surfaces. This warm-up brings the engine to reasonably steady temperatures and performance, so the results can be considered representative of steadystate operation.

\section{OPTICAL DIAGNOSTICS}

\section{LASER-INDUCED FLUORESCENCE}

The principal optical diagnostic employed in this work is gasoline LIF. When excited by UV light, UTG-96 produces a strong fluorescence signal that is related to its mass distribution. Multiple components of the gasoline contribute to the signal. The fact that at least some of these components are susceptible to oxygen quenching means it is difficult to make the gasoline measurements quantitative [10]. The alternative approach of using a custom blend of fuel hydrocarbons and quench-free fluorescent tracers is hindered by the difficulty of matching spray, evaporation, and combustion behavior to that of gasoline. For this study, we use gasoline exclusively as the fuel, and the LIF results presented are qualitative.

A frequency-quadrupled $\mathrm{Nd}$ :YAG laser $(266 \mathrm{~nm})$ with a typical energy of $40 \mathrm{~mJ}$ per pulse provides excitation for LIF. The beam is expanded (flood LIF) and directed into the cylinder from below via the Bowditch mirror and piston window. The excited fluorescence is recorded using 8-bit Xybion intensified CCD cameras. For several of the LIF experiments, two cameras capture simultaneous images from orthogonal viewpoints. One camera views along the same path as the laser by means of a beamsplitting mirror ("Bowditch view" in Figure 1). The second camera views from the side, through the quartz cylinder ("side view"). To exclude extraneous light, the intensifier gate time is set at $100 \mathrm{~ns}$. The fluorescence signal is collected with glass lenses that block unwanted UV light.

\section{DIRECT FLAME IMAGING}

A second optical technique, direct flame (spontaneous emission) imaging, is used to characterize the ignition and burning of pool fires in the research engine. As in the LIF technique, two cameras are used to capture both 
Bowditch- and side-view images of the flames. An intensifier gate duration of $10 \mu \mathrm{s}$ is sufficiently fast to freeze the pool fires.

\section{LASER ELASTIC SCATTERING}

A final diagnostic technique, laser elastic scattering, is used to detect in-cylinder particulate matter formed by pool fires. For these experiments, the Nd:YAG laser is frequency-doubled to produce visible light pulses at 532 $\mathrm{nm}$. Two versions of this technique are employed: flood and planar.

In the flood version, an expanded beam is directed through the piston window to illuminate the cylinder volume, and two cameras are positioned to record opposing side views. One camera, using a fast 100-ns gate synchronized with the laser pulse, captures a soot scattering image. The gate on the other camera is offset in time by $5 \mu$ s to exclude laser light and record only flame luminosity. The resulting image pairs are thus independent and effectively simultaneous.

In the planar laser elastic scattering version, a single camera records soot scattering through the Bowditch window. The laser light is formed into a $0.5-\mathrm{mm}$-thick horizontal sheet and positioned $3 \mathrm{~mm}$ below the fire deck. The laser is pulsed when the piston top is located $6 \mathrm{~mm}$ below the fire deck (340 CAD). With this arrangement, measurements of soot scattering can be made near the end of the exhaust stroke.

\section{LIF OF FUEL FILMS}

\section{FUEL FILM FORMATION}

Piston-top fuel films are created when fuel spray penetrates to the piston top and impinges on the piston surface. This process is illustrated in Figure 3 , which shows simultaneous side and Bowditch views of the liquid-phase fuel recorded using flood LIF.

As in all the following LIF figures, each image in Figure 3 is an average of 4 recorded frames. To aid in comparison, the gains for all images in a given sequence are adjusted to be equal. Labels in the figures-either image-capture or start of injection (SOI) times-are in units of crank angle degrees (CAD) ranging from -360 to $+360 \mathrm{CAD}$, with $0 \mathrm{CAD}$ representing top center of compression. In Figure 3 , the fuel is injected at -90 $\mathrm{CAD}$, midway through the compression stroke.

The upper row of images in Figure 3 shows progressive side views of the injection event. In these images, the rising piston is represented in gray, and the area of each image represents the full cylinder cross-section. The first image was recorded at -85 CAD (5 CAD after SOI), with the spray just visible below the fire deck. By $-77.5 \mathrm{CAD}$ (the approximate end of injection), the spray has begun to impinge on the piston top. By the time of the fourth

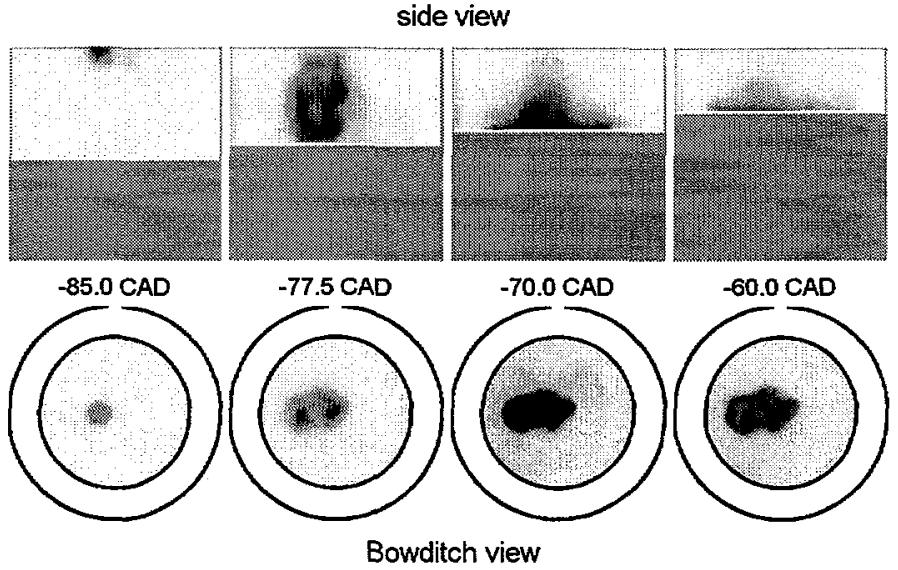

Figure 3: Fuel spray impingement on piston top visualized by flood LIF of gasoline injected at SOI $=-90 \mathrm{CAD}$. Image-capture times are listed between each pair of images. The linear gray scale is reversed, so that greater pixel intensities appear darker.

image, there is relatively little signal from suspended droplets - they have either evaporated or contributed to the piston-top film. No LIF signal from vapor-phase components is visible in these images due to the low intensifier gain.

The lower row of images in Figure 3 comprises bottom views of the film formation process. In these images, the inner and outer circles represent the extents of the piston window and bore, respectively. Note that the spray is visible before it hits the piston surface; thus, this view cannot be used to determine the moment of spray impact. By $-70 \mathrm{CAD}$, the piston-top fuel film is strongly delineated. Its width appears smaller than the spray cloud in the corresponding side view-likely a result of the significant difference in optical pathlengths. The fuel film is located left of center due in part to a 7-mm offset of the injector in that direction. Tumble motion may also contribute to directing the spray toward the left side. An analysis of spray-wall interaction and splash dynamics is beyond the scope of this work, but modeling of this topic is covered in the literature [11-13].

\section{QUENCHING OF LIQUID-PHASE FLUORESCENCE}

Oxygen quenching of fluorescence is a well-known problem for LIF detection of vapor-phase species. It is less widely known among the engine research community that oxygen quenching also affects liquidphase fluorescence. A demonstration of this phenomenon is presented in Figure 4. Gasoline films were created on the piston surface by injecting early in the intake stroke, and the resulting fluorescence signal was recorded at five crank angle positions during the compression and expansion strokes. To evaluate oxygen quenching, the experiment was performed with (top sequence of 5 images) and without (bottom sequence) oxygen. In an air environment, the LIF signal weakens dramatically as pressure (and oxygen concentration) increase near top center. In a nitrogen environment, the five images show a steady signal strength regardless of pressure. 


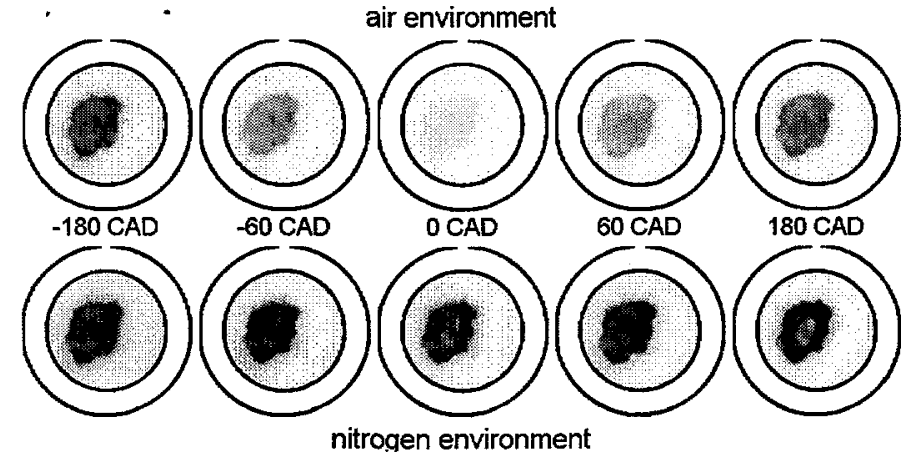

Figure 4: Oxygen quenching of fluorescence from liquid gasoline films. Fuel sprays were injected at $-320 \mathrm{CAD}$ into the motored engine. Image-capture times are listed between each pair of images. For this experiment only, head temperature was lowered to $40^{\circ} \mathrm{C}$ to reduce film evaporation. Cylinder pressures corresponding to the 5 imagecapture times were respectively: $50,190,910,170$, and $110 \mathrm{kPa}$. A non-linear gray scale is used to boost the weaker signals.

Quenching of liquid-phase fluorescence also occurs during LIF visualization of sprays in an air environment. We have observed that the LIF signal from a late-inject gasoline spray (high ambient pressure) is weak compared to an early-inject spray (low pressure). In a nitrogen environment, spray image intensity is unaffected by ambient pressure.

The cause of fluorescence quenching in the liquid phase is dissolved oxygen. Oxygen in solution is known to strongly quench some organic molecules [14]. In the engine, cylinder compression increases the partial pressure of gaseous oxygen, in turn raising the concentration of oxygen in any fuel films present; the corresponding fluorescence efficiency decreases [15]. Note that the results summarized in Figure 4 indicate that the time constant for dissolution of oxygen in the films is short compared to the engine cycle time. Operating in a nitrogen environment eliminates the oxygen quenching problem; for the experiments reported here, however, fired operation was mandatory to establish appropriate engine surface temperatures. Thus, interpretation of the LIF results reported below necessitates an awareness of pressure sensitivity.

\section{FUEL FILM DURATION}

The duration of fuel films on the piston top during an engine cycle is demonstrated in Figure 5. Gasoline

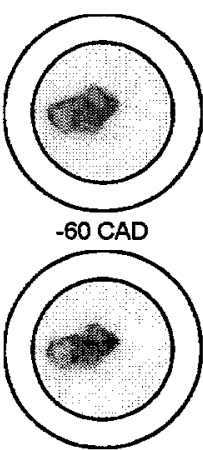

$60 \mathrm{CAD}$

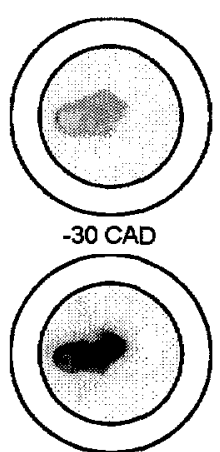

$120 \mathrm{CAD}$

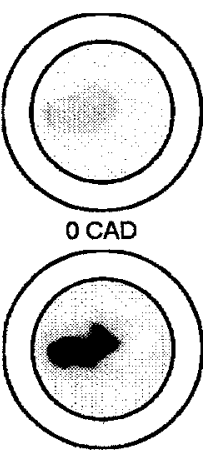

$180 \mathrm{CAD}$

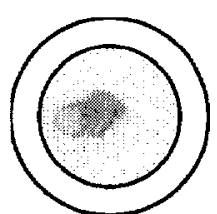

$30 \mathrm{CAD}$

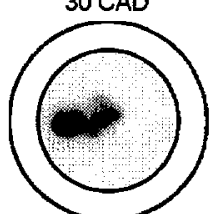

$360 \mathrm{CAD}$
Figure 5: LIF from piston-top fuel films for late injection (SOI $=-90$ CAD). Image-capture times are listed below each image. fluorescence does not provide information about which of the fuel components persist, but volatile components in the spray are likely to evaporate prior to-or soon after-impingement on the piston. However a significant amount of liquid persists through the expansion and exhaust strokes and into the next cycle as demonstrated in Figure 5. The persistence of liquid films longer than a cycle has been observed previously in other engines $[16,17]$.

The effects of oxygen quenching are apparent in Figure 5. The LIF signal nearly disappears by 0 CAD but then recovers, reaching a maximum near $180 \mathrm{CAD}$. This is consistent with the increase of oxygen partial pressure during the compression stroke, and its subsequent decrease due to reaction and volume expansion during the expansion stroke.

For early injection, the fuel films evaporate much earlier in the cycle as seen in Figure 6. In this case, the fuel is injected early during the intake stroke while the piston is close to the injector, producing a substantial fuel film. Between -300 and $-180 \mathrm{CAD}$, the signal drops significantly even though the cylinder pressure is approximately constant throughout that period, implying significant evaporation of the fluorescent components. As in the late-injection case, the signal continues to weaken during the compression stroke, due to a combination of evaporation and oxygen quenching. In contrast to late injection though, the signal from early-inject films does not recover after top center, indicating that the fluorescent liquid components have mostly evaporated by the end of the expansion stroke.

\section{EFFECTS OF INJECTION TIMING}

In a previous study [8], we have observed that elevated fuel temperature not only produces a narrow, filled spray cone, but also leads to increased spray penetration. At our elevated head (fuel) temperature, fuel spray impinges on the piston top at all injection timings, as shown in Figure 7. In this figure, piston-top fuel films were recorded $30 \mathrm{CAD}$ after $\mathrm{SOI}$ for a range of injection timings. As expected, the mass of fuel impacting the piston is significantly greater for early and late injections, when the piston is close to the injector.

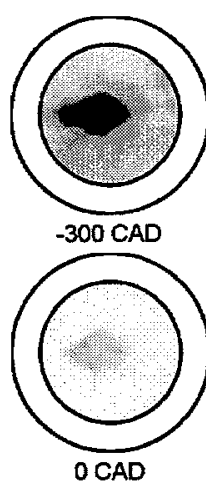

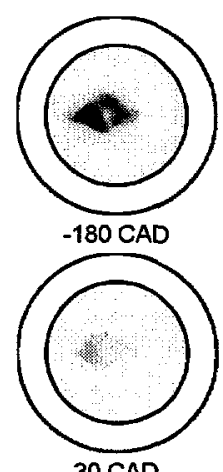

$30 \mathrm{CAD}$

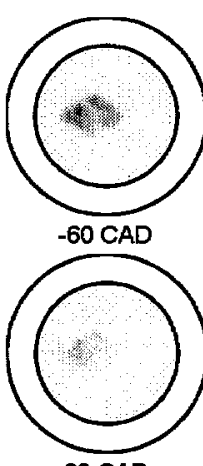

$60 \mathrm{CAD}$

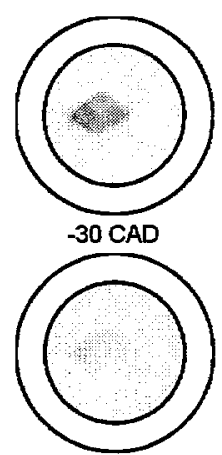

$180 \mathrm{CAD}$
Figure 6: LIF from piston-top fuel films for early injection ( $\mathrm{SOI}=-320$ CAD). Image-capture times are listed below each image. 


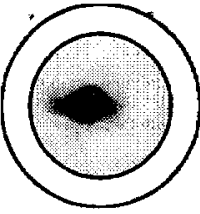

$\mathrm{SOI}=-320 \mathrm{CAD}$

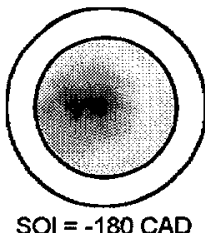

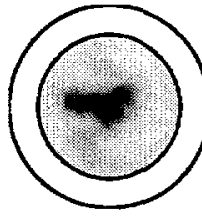
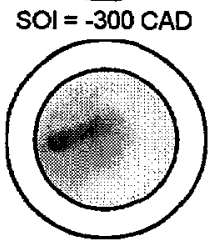

SOI $=-150 \mathrm{CAD}$

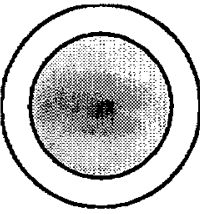

$S O I=-270 \mathrm{CAD}$

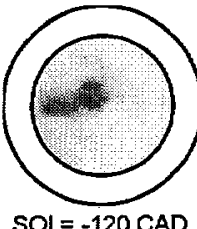

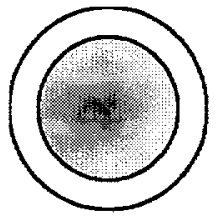

$\mathrm{SOI}=-210 \mathrm{CAD}$

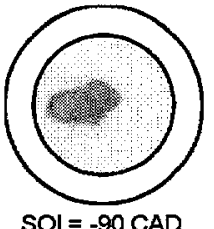

Figure 7: Fuel film formation as a function of injection timing. LIF images recorded $30 \mathrm{CAD}$ after SOI.

While fuel films are created at all injection timings, only early and late injections produce films that persist through the compression stroke. Figure 8 shows fuel films recorded at the approximate time of spark for a range of injection timings. For the earliest injections (SOI -320 and $-300 \mathrm{CAD}$ ), a measurable fuel film remains on the piston at the time of spark. However, these films behave differently than late-injection films. As seen in Figure 6, the early-inject films disappear during the expansion stroke, and contain possibly only heavy ends (including fluorescent components) at the time of spark. Further evidence of differing behavior-these early-inject films do not ignite-is discussed in the Direct Imaging of Pool Fires section below.

For mid-range injection timings a characteristic fluorescence signal arises from liquid fuel films on the injector tip and on the adjacent edges of the intake valves. This signal-a dot on the injector tip and two short arcs of the valve contours-is barely visible just left of center in the SOI -270 to -180 CAD images in Figure 8 . These valve films are the result of spray impingement during open-valve (intake-stroke) injections. Note, however, that for these mid-range injection timings, no piston-top films remain at the time of spark.

For later injections (SOI -150 CAD and later in Figure 8), fuel is again visible on the piston surface at the time of spark. The quantity of fuel in the films increases as injection is retarded, due to both the decreasing distance between injector and piston at the time of injection, and the decreasing time for evaporation. In contrast to the
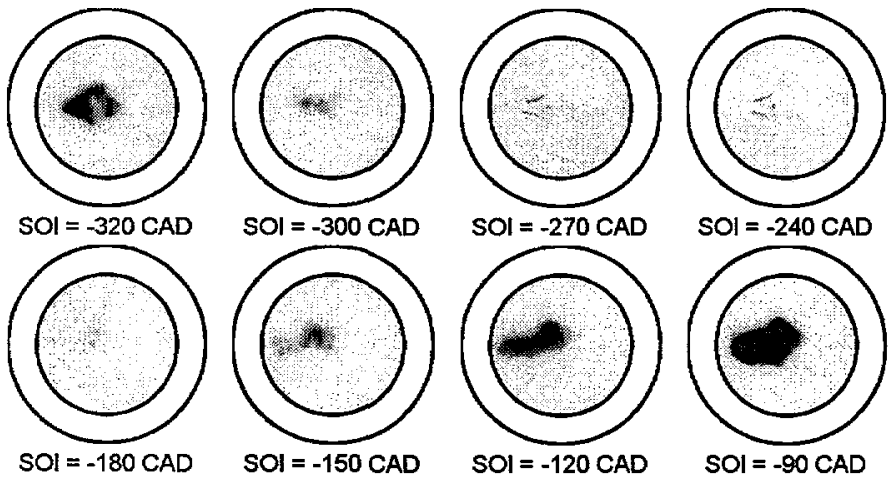

Figure 8: Fuel films at time of spark $(-30 \mathrm{CAD})$ for a range of injection timings.
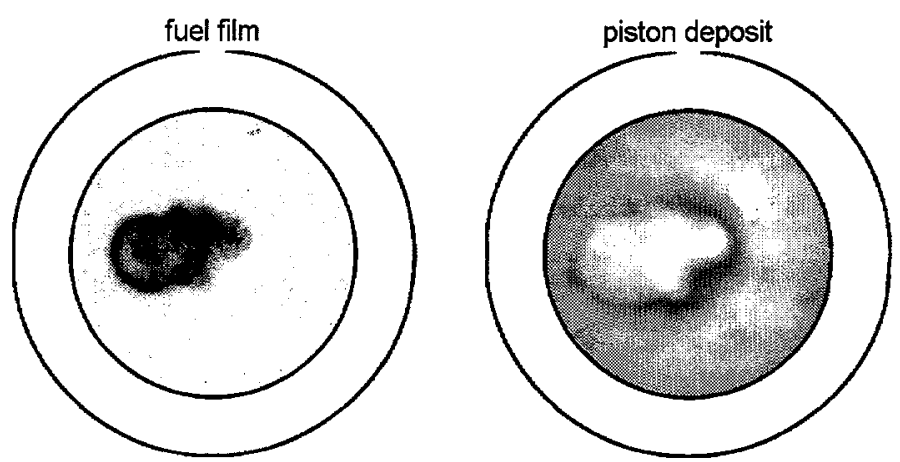

Figure 9: Fuel film compared with piston deposit for late-injection experiment $(S O I=-90 \mathrm{CAD}$ ). Fuel film image is a typical LIF image recorded $65 \mathrm{CAD}$ after SOI. Piston deposit image is a backlit, visiblelight image recorded after approximately 100 fired cycles.

early-inject films, the late-inject films ignite, as discussed below.

\section{PISTON DEPOSITS}

Carbonaceous deposits on the piston surface are observed following late-injection experiments, and these deposits bear a close relationship to the shape and position of the fuel films. The deposits accumulate rapidly, becoming noticeable after only a few hundred fired cycles, and are thicker for later injection timings. In initial stages, the deposit appears to form an outline of the fuel film, as shown in Figure 9. As more fired cycles occur, the deposits fill in gradually, forming a continuous layer similar in shape and location to the fuel films. A fully developed piston deposit is shown in Figure 10. Cleaning the piston top before each experiment assures that deposits do not block the film LIF imaging.

\section{DIRECT IMAGING OF POOL FIRES}

\section{IGNITION OF POOL FIRES}

At our piston temperatures and low fuel equivalence ratio, pool fires ignite when a significant amount of volatile fuel remains on the piston surface at the time of the premixed burn. To examine the ignition of pool fires, two cameras are used to record simultaneous side and

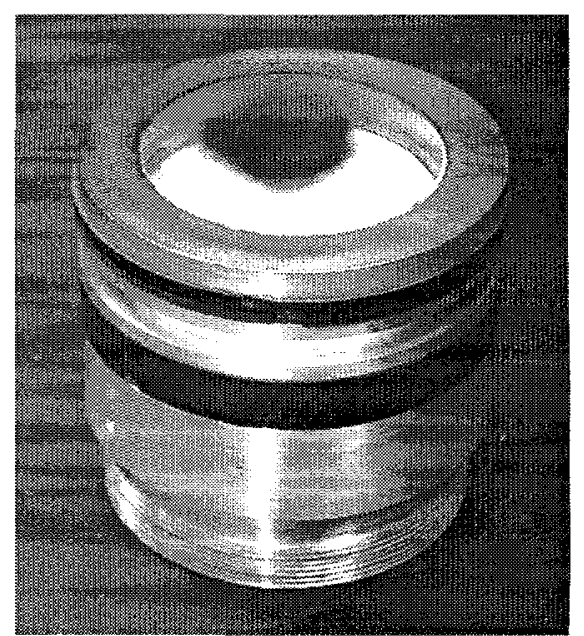

Figure 10: Piston-top carbon deposit after several thousand fired cycles with late injection (SOI $=-90 \mathrm{CAD}$ ). 


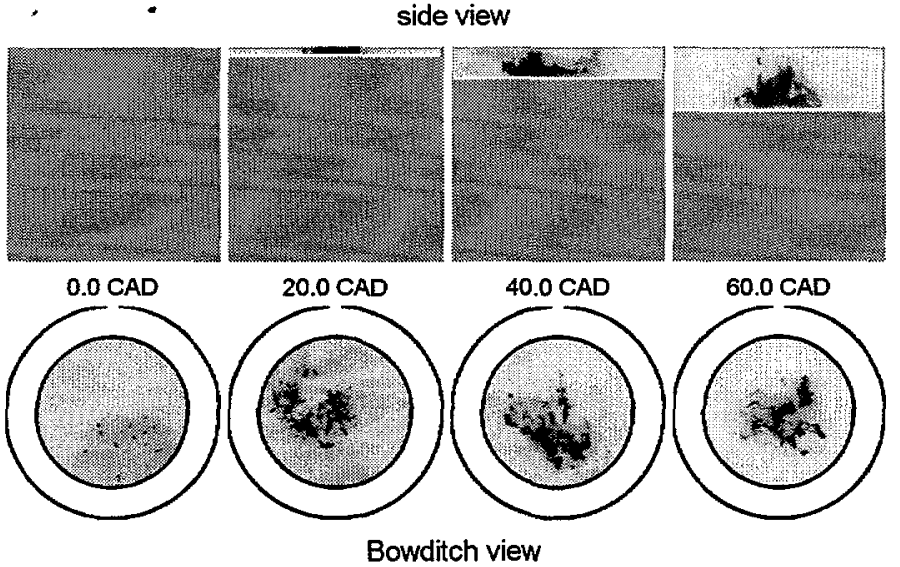

Figure 11: Simultaneous side and Bowditch views of visible pool fire luminosity for late injection ( $\mathrm{SOI}=-90 \mathrm{CAD}$ ). Image-capture times are listed between each pair of images.

Bowditch views of visible flame luminosity. The four image pairs in Figure 11 have been selected to illustrate typical pool fire ignition. Once ignition occurs, these flames burn with a bright yellow color that is characteristic of incandescent soot.

The first Bowditch-view image of Figure 11 (0 CAD) shows that pool fires ignite in isolated locations as the premixed flame propagates across the cylinder. As the cycle proceeds, the isolated flames consolidate. The Bowditch-view images demonstrate that the fires are located near the center of the piston; flames along the perimeter of the field of view are rarely observed.

In the side-view images of Figure 11, the flames are first visible at $20 \mathrm{CAD}$ as the piston descends below the fire deck. The flames are attached to the fuel film on the piston top and follow the piston as it descends. Luminosity from premixed flames is not visible in either view since the gain has been adjusted to prevent detector saturation by the much brighter luminosity of the pool fires.

\section{DEVELOPMENT OF POOL FIRES}

After ignition, pool fires burn close to the piston top and can persist through the expansion and exhaust strokes as depicted in Figure 12. Toward the end of the cycle, pool fire luminosity weakens and the flames appear to lift off the surface of the piston as seen in the $240 \mathrm{CAD}$ image of Figure 12. By $300 \mathrm{CAD}$, the flames have extinguished, although some liquid film still remains (see Figure 5). We conclude that the remaining liquid is no longer sufficiently volatile, or oxygen concentration has fallen too low, to sustain a flame.

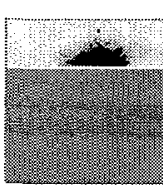

$60 \mathrm{CAD}$

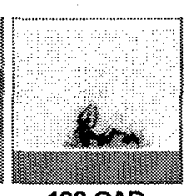

$120 \mathrm{CAD}$

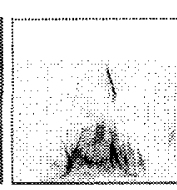

$180 \mathrm{CAD}$

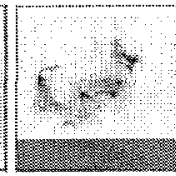

240 CAD

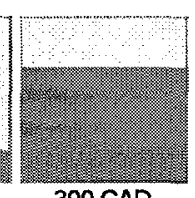

$300 \mathrm{CAD}$
Figure 12: History of pool fire luminosity through expansion and exhaust strokes. SOI $=-90 \mathrm{CAD}$. Image-capture times are listed below each image.

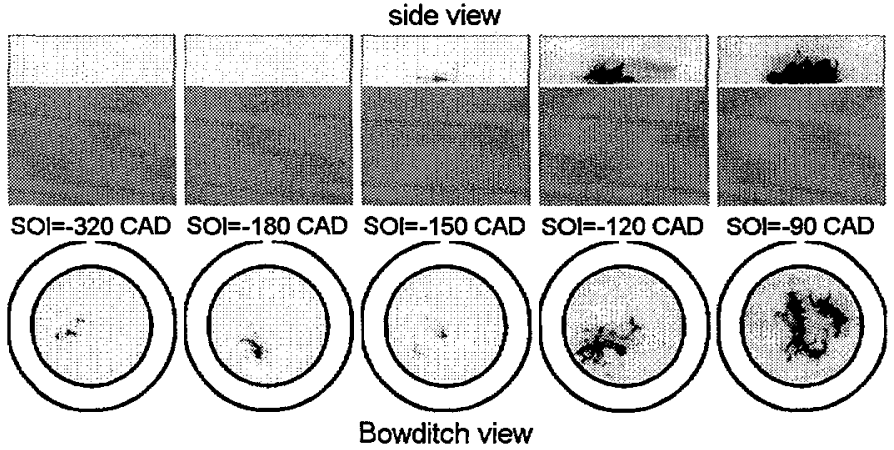

Figure 13: Simultaneous side and Bowditch views of pool fire luminosity for a range of SOI timings. All images are recorded at 60 CAD.

\section{EFFECTS OF INJECTION TIMING}

Injection timing is a significant factor controlling the ignition of pool fires, due to its influence on spray impingement and film evaporation time. To illustrate this point, Figure 13 displays visible-light images recorded at 60 CAD (expansion stroke) for a range of injection timings. The 60 CAD image-capture time was selected since all observed pool fires were burning at this time.

The results of Figure 13 lead to the important conclusion that no piston-top pool fires occur for intake-stroke injections. Some flame luminosity is visible in the SOI 320 and -180 CAD images (Bowditch view), but this is caused by small flames attached to the intake valves following early injection. As mentioned in the LIF of Fuel Films section, fuel films are formed at this location when spray strikes the valves during open-valve injection. The resulting valve-seat pool fires are located within the pent roof volume and thus are not visible in the side-view images.

For most injection timings during the intake stroke, the lack of pool fires is explained by the disappearance of fuel films by the time of spark (see Figure 8). However some film remains at the time of spark for the earliest injection times (SOI $-320 \mathrm{CAD}$ ). To explain the lack of pool fires at these conditions, we hypothesize that the lighter, more volatile fuel components have evaporated by the time of spark, leaving a reduced film of heavier components which fluoresce but do not ignite.

As illustrated in Figure 13, pool fires ignite consistently for late-injection timings. In the SOI -150 CAD image pair, some flame luminosity can be seen on top of the piston in both views. For later injections, the pool fires tend to increase in size and luminosity. The occurrence of these intense pool fires represents an important consequence of piston wetting in DISI engines.

\section{LASER ELASTIC SCATTERING OF SOOT}

\section{DEVELOPMENT OF SOOT}

A further important consequence of piston wetting and pool fires is the associated production of particulate matter. The flood laser scattering technique produces 


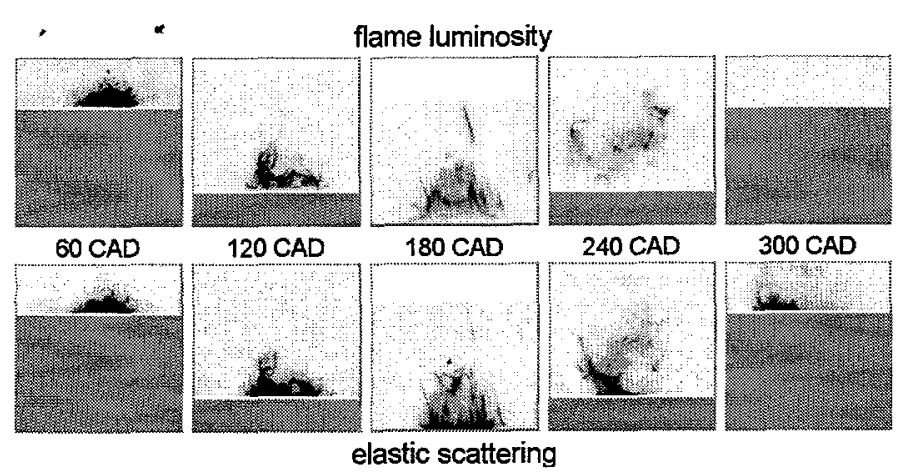

Figure 14: Flame luminosity images repeated from Figure 12, paired with simultaneous flood laser elastic scattering images. $\mathrm{SOI}=-90$ $\mathrm{CAD}$. Image-capture times are listed between each pair of images.

simultaneous pool fire luminosity and soot scattering images, as shown in Figure 14. The image pairs show a strong correlation since pool fire luminosity is primarily due to incandescent particles, and these same particles are responsible for laser elastic scattering. At later times in the cycle, however, some differences in the images are apparent. At 180 and $240 \mathrm{CAD}$, the pool fire has begun to lift from the piston top while the soot scattering signal remains attached to the piston surface. At 300 CAD, the pool fire has extinguished while some soot signal remains. Based on these observations, we conclude that significant soot is produced during the pool fire burn, with a portion of it remaining close to the piston top even after the flames have apparently extinguished.

\section{SOOT AT END OF EXHAUST}

The flood laser elastic scattering measurements suggest that significant soot may persist in the cylinder to the end of the exhaust stroke in cycles where pool fires ignite. However, the flood technique is not well suited to record late-cycle soot since the rising piston obscures the view. Instead the planar technique is employed with the laser sheet positioned just below the fire deck.

Figure 15 presents planar elastic scattering images recorded late in the exhaust stroke for five different SOI timings. Consistent with the fuel film and pool fire results, late injections (SOI -90 and $-120 \mathrm{CAD}$ ) generate the most soot, and this soot persists to the end of the exhaust stroke. The image representing injection at SOI -150 CAD shows a small amount of soot, consistent with the smaller fuel films and pool fires associated with that injection timing. As expected from the lack of pool fires, no soot is detected for intake-stroke injections.

All images in Figure 15 were recorded at 340 CAD; attempts to detect soot in this plane at earlier times in the exhaust stroke failed. This is further evidence that the soot remains close to the piston top as the piston rises. Because the image plane in Figure 15 is close to the exhaust valves, and image timing is near to top center, we conclude that the detected soot is likely to exit the cylinder with the last of the exhaust flow and contribute to engine-out particulate emissions. These results suggest future experiments to measure incylinder and engine-out particulates simultaneously.

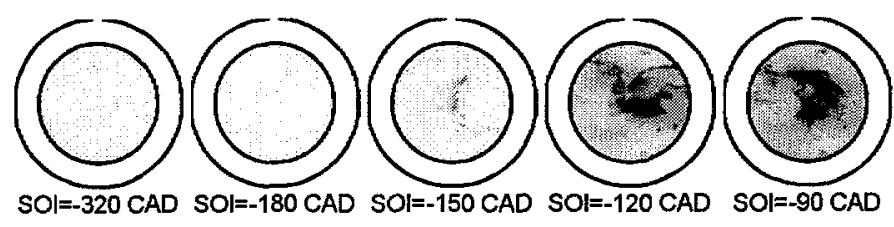

Figure 15: Planar laser elastic scattering signal from soot recorded at $340 \mathrm{CAD}$ for various injection timings.

\section{CONCLUSION}

A combination of optical diagnostics applied to a singlecylinder DISI research engine has revealed the close relationship between piston-top fuel films, pool fires, and particulate matter. Because DISI engine designs vary significantly, the experiments described in this paper are not intended to determine conditions that will create pool fires for all engines, but rather to highlight the problem, explore the processes that lead to pool fires, and discuss potential consequences.

LIF of gasoline has been used to investigate qualitatively the spray impingement and fuel film formation on the piston surface. Oxygen quenching has been found to reduce fluorescence yield from liquid gasoline at elevated pressures. The location of the piston with respect to the fuel injector and the amount of time for evaporation are major factors in the existence of fuel films at time of spark. It is also expected that engine geometry, piston temperature, and fuel injector design would have significant effects upon fuel film formation.

Piston-top pool fires have been visualized with direct flame imaging. They are located on the piston surface, follow the motion of the piston top, and can burn until midway through the exhaust stroke. Except for the earliest injection timings, the existence of fuel films at time of spark correlates with the ignition of pool fires. The exception is likely due to differential evaporation of the gasoline components. Late injections, where significant amounts of fuel impinge on the piston and little time is available for evaporation, create conditions most conducive to pool fires.

The detrimental effects of pool fires go beyond obvious fuel efficiency issues. In these experiments, their link to piston-top carbon deposits and soot production is demonstrated. Significant amounts of particulate matter are produced by the pool fires, creating a likely source of engine-out emissions.

\section{ACKNOWLEDGMENTS}

The authors acknowledge the technical guidance provided by our industrial partners from the U.S. Council for Automotive Research (USCAR): Rick Anderson (Ford), Paul Najt (General Motors), and Fu-Quan Zhao (DaimlerChrysler). This work was performed at the Combustion Research Facility of Sandia National Laboratories and was funded by the U.S. Department of Energy, Office of Transportation Technologies, Office of Advanced Automotive Technologies under the direction of Rogelio Sullivan. 


\section{CONTACT}

Richard Steeper: steeper@sandia.gov

Eric Stevens: eric.stevens@ae.ge.com

\section{REFERENCES}

1. F. Zhao, M.-C. Lai, and D. L. Harrington, "Automotive Spark-Ignited Direct-Injection Gasoline Engines," Progress in Energy and Combustion Science 25: 437-562, 1999.

2. T. Nogi, Y. Ohyama, T. Yamauchi, and H. Kuroiwa, "Mixture Formation of Fuel Injection Systems in Gasoline Engines," SAE Paper 880558, 1988.

3. Y. Ohyama, M. Ohsuga, and H. Kuroiwa, "Study On Mixture Formation and Ignition Process in Spark Ignition Engine Using Optical Combustion Sensor," SAE Paper 901712, 1990.

4. Y. Ohyama, T. Nogi, and M. Ohsuga, "Effects of Fuel/Air Mixture Preparation of Fuel Consumption and Exhaust Emission in a Spark Ignition Engine," SAE Paper 925023, 1992.

5. K. Song, E. Clasen, C. Chang, S. Campbell, and K. T. Rhee, "Post-Flame Oxidation and Unburned Hydrocarbon in a Spark-Ignition Engine," SAE Paper 952543, 1995.

6. P. O. Witze and R. M. Green, "LIF and Flame-Emission Imaging of Liquid Fuel Films and Pool Fires in an SI Engine During a Simulated Cold Start," SAE Paper 970866, 1997.

7. Y. Iwamoto, K. Noma, O. Nakayama, T. Yamauchi, and H. Ando, "Development of Gasoline Direct Injection Engine," SAE Paper 970541, 1997.

8. R. R. Steeper and E. J. Stevens, "Characterization of Combustion, Piston Temperatures, Fuel Sprays, and FuelAir Mixing in a DISI Optical Engine," SAE Paper 2000-01$2900,2000$.

9. P. M. Najt, GM Research, personal communication, 1999.

10. T. Itoh, A. Kakuho, H. Hishinuma, T. Urushihara, Y. Takagi, K. Horie, M. Asano, E. Ogata, and T. Yamashita, "Development of a New Compound Fuel and Fluorescent Tracer Combination for Use with Laser Induced Fluorescence," SAE Paper 952465, 1995.

11. Z. Han, Z. Xu, and N. Trigui, "Spray/Wall Interaction Models for Multidimensional Engine Simulation," International Journal of Engine Research 1(1): 127-146, 2000.

12. P. J. O'Rourke and A. A. Amsden, "A Spray/Wall Interaction Submodel for the KIVA-3 Wall Film Model," SAE Paper 2000-01-0271, 2000.

13. M. F. Trujillo, W. S. Mathews, C. F. Lee, and J. E. Peters, "Modelling and Experiment of Impingement and Atomization of a Liquid Spray on a Wall," International Journal of Engine Research 1(1): 87-105, 2000.

14. G. G. Guilbault, Practical Fluorescence, Marcel Dekker, Inc., New York, 1973.

15. C. A. Parker, Photoluminescence of Solutions, Elsevier, London, 1968.

16. J. Li, R. D. Matthews, R. H. Stanglmaier, C. E. Roberts, and R. W. Anderson, "Further Experiments on the Effects of In-Cylinder Wall Wetting on HC Emissions from DirectInjection Gasoline Engines," SAE Paper 1999-01-3661, 1999.

17. R. H. Stanglmaier, J. Li, and R. D. Matthews, "The Effect of In-Cylinder, Wall-Wetting Location on the HC Emissions from SI Engines," SAE Paper 1999-01-0502, 1999. 